\title{
A pereira cv. Rocha
}

Ivan Dagoberto Faoro', André Amarildo Sezerino', Mariuccia Schlichting De Martin e Mateus da Silveira Pasa²

Resumo - Neste artigo são comentadas as características agronômicas da planta, os porta-enxertos, os cultivares polinizadores, a colheita e a armazenagem dos frutos do cv. Rocha. Essa pereira foi originada em Portugal e atualmente é plantada nas regiões mais frias no Sul do Brasil. Seus frutos são de pequenos a médios, com formato piriforme e excelente qualidade para consumo in natura. Tem elevada resistência ao manuseio e bom período de armazenagem pós-colheita, mas é suscetível a entomosporiose e sarna.

Termos para indexação: cultivar; doenças; porta-enxertos; polinização; armazenagem.

\section{The cv. Rocha pear tree}

Abstract - This article presents and discusses the agronomic characteristics, rootstocks, pollinator cultivars, harvest and storage of the $\mathrm{cv}$. Rocha plant. This pear tree originates from Portugal and is currently cultivated in colder regions of Brazil, especially the Southern. Its fruits range from small to medium-size, have a pyriform shape and excellent quality for in natura consumption. The fruit has high resistance to handling and a good period of post-harvest storage, but this cultivar is susceptible to Fabraea leaf spot and scab.

Index terms: cultivar; diseases; rootstock; pollination; storage.

\section{Tipo e clima}

O cv. Rocha é uma pereira do tipo europeia da espécie Pyrus communis. Geralmente é destinada para ao consumo in natura, mas pode ser utilizada para conserva. Apresenta média exigência em frio, e o seu plantio pode se dar em regiões acima de $800 \mathrm{~m}$ de altitude, do Meio- Oeste até o Planalto Catarinense, com mais de 1.000 unidades de frio pelo método Carolina do Norte Modificado ou com 550 horas $\leq 7,2^{\circ} \mathrm{C}$ (FAORO et al., 2017). Nestas condições, necessita da aplicação de produtos indutores da brotação para proporcionar a "quebra" da dormência.

\section{Origem}

É uma variedade portuguesa obtida casualmente em 1836, a partir de semente (SOARES et al., 2001). No Brasil, o plantio em escala comercial se iniciou na década de 1990, nas regiões de São
Joaquim e de Urubici, em Santa Catarina, sendo plantadas por produtores vindos de Portugal.

\section{Planta}

A planta tem vigor médio, sendo menos vigorosa que a 'Yali'. A maior parte de sua produção dá-se em esporões, seguido depois em brindilas e, em menor quantidade, em ramos mistos. Os frutos oriundos de brindilas são maiores. Pode atingir produtividade $55,8 \mathrm{t} \mathrm{ha}^{-1}$ na "sétima folha" nas condições de Vacaria, RS (FIORAVANÇO et al., 2016).

Diversos pomares têm registrado baixa fixação de frutos. Muitas vezes, tal situação se deve à implantação do pomar sem ou com poucas plantas polinizadoras. A solução desse problema envolve o plantio de maior quantidade de plantas polinizadoras por área e a disponibilização de maior quantidade de insetos polinizadores, como as abelhas.

\section{Doenças e distúrbios}

É suscetível à sarna (Venturia pyrina), a podridões (Penicilium spp.) (SOARES et al., 2001) e à entomosporiose (Entomosporium mespeli). É medianamente resistente ao fogo selvagem (Erwinia amylovora).

Seus frutos são suscetíveis ao escurecimento de polpa, ao desenvolvimento de russeting, a ferimentos epidérmicos (danos por atrito), e à escaldadura superficial. Estão sujeitos ao ataque por podridões causadas por Botrytis cinerea (podridão cinzenta), Penicillium expansum (podridão azul), Rhizopus spp. e Monilia fructigena (moniliose).

A planta e seus frutos estão sujeitos a danos por insetos, principalmente os causados por mosca-das-frutas (Anastrepha fraterculus), ácaros (Panonychus spp., Tetranychus spp. e Eriophyes spp.), cochonilha-piolho-de -são-josé (Comstockaspis perniciosa) e mariposa oriental (Grapholita molesta). 


\section{Porta enxertos}

Apresenta boa compatibilidade com Pyrus calleryana e Pyrus betulaefolia, os quais induzem alto vigor (FAORO et al., 2016) e exigem um adequado manejo da planta. A entrada em produção nesses porta-enxertos é tardia e irregular. Para reduzir o vigor podem ser utilizados marmeleiros. Apresenta boa compatibilidade com o 'BA 29', mediana com o 'EM-A' e pior com o 'EM-C'. No Brasil, plantio sobre 'Adams' em espaçamento de $4,0 \mathrm{~m} \times 1,0 \mathrm{~m}$ e sobre 'EM-C' com espaço de $4,0 \mathrm{~m} \times 0,5 \mathrm{~m}$, tem gerado boas produtividades (FIORAVANÇO et al., 2016). Para locais com solos rasos e rochosos, como os da região de São Joaquim, o porta-enxerto 'BA 29' é o mais indicado dentre os marmeleiros, pelo fato de ser mais vigoroso que o 'EM-A' e o 'EM-C'. Caso existam problemas de incompatibilidade com diferentes marmeleiros, podem ser utilizados filtros de 'Beurre Hardy' ou 'Decana du Comice'.

\section{Polinização}

As plantas de 'Rocha', em média, florescem entre 14 de setembro a 10 de outubro. Suas flores são xenogâmicas e possuem os alelos de incompatibilidade gametofítica S101/S105. Mesmo assim, podem produzir frutos partenocárpicos. Por isso, sua polinização requer pólen compatível oriundo de outro cultivar para elevar a fixação e a produção de frutos. Como polinizadores, nas regiões mais frias do Sul do Brasil, podem ser utilizados os cultivares 'Housui' (S103/ S105), 'Packham's Triumph' (S101/ S103) (SEZERINO \& ORTH, 2015) e 'Max Red Bartlett' (S101/S102). Uma nova opção de polinizador é o novo cultivar SCS421 Carolina, que produz peras do tipo japonesa. Na região de São Joaquim também podem ser utilizados como polinizadores os cultivares 'Abate Fetel' e 'Santa Maria', devido à coincidência de floração.

Deve ser considerada a característica das flores de pereira de produzirem pouca quantidade de néctar e de este possuir baixo teor de açúcar, sendo pouco atrativo para as abelhas, as quais procuram outras fontes de néctar mais atrativas. Como medida de mitigação, sugere-se a introdução de seis colmeias ha-1 em duas épocas: a metade com $10 \sim 20 \%$ das flores abertas e o restante na plena floração. Em áreas com maior intensidade de ventos, mais frias e úmidas, o número de colmeias pode subir para até oito ha-1.

\section{Frutos}

A pera 'Rocha' apresenta alta aceitação comercial, excelente qualidade nutricional e alta capacidade de armazenamento. $\mathrm{O}$ seu fruto é simétrico e de formato entre piriforme-ovalado e redondo-ovalado. Sua casca é de coloração verde-clara quando imaturo e amarelo-palha quando maduro, podendo algumas vezes apresentar uma mancha tenuamente rosada no lado exposto ao sol (Figura 1). 0 russeting sobre
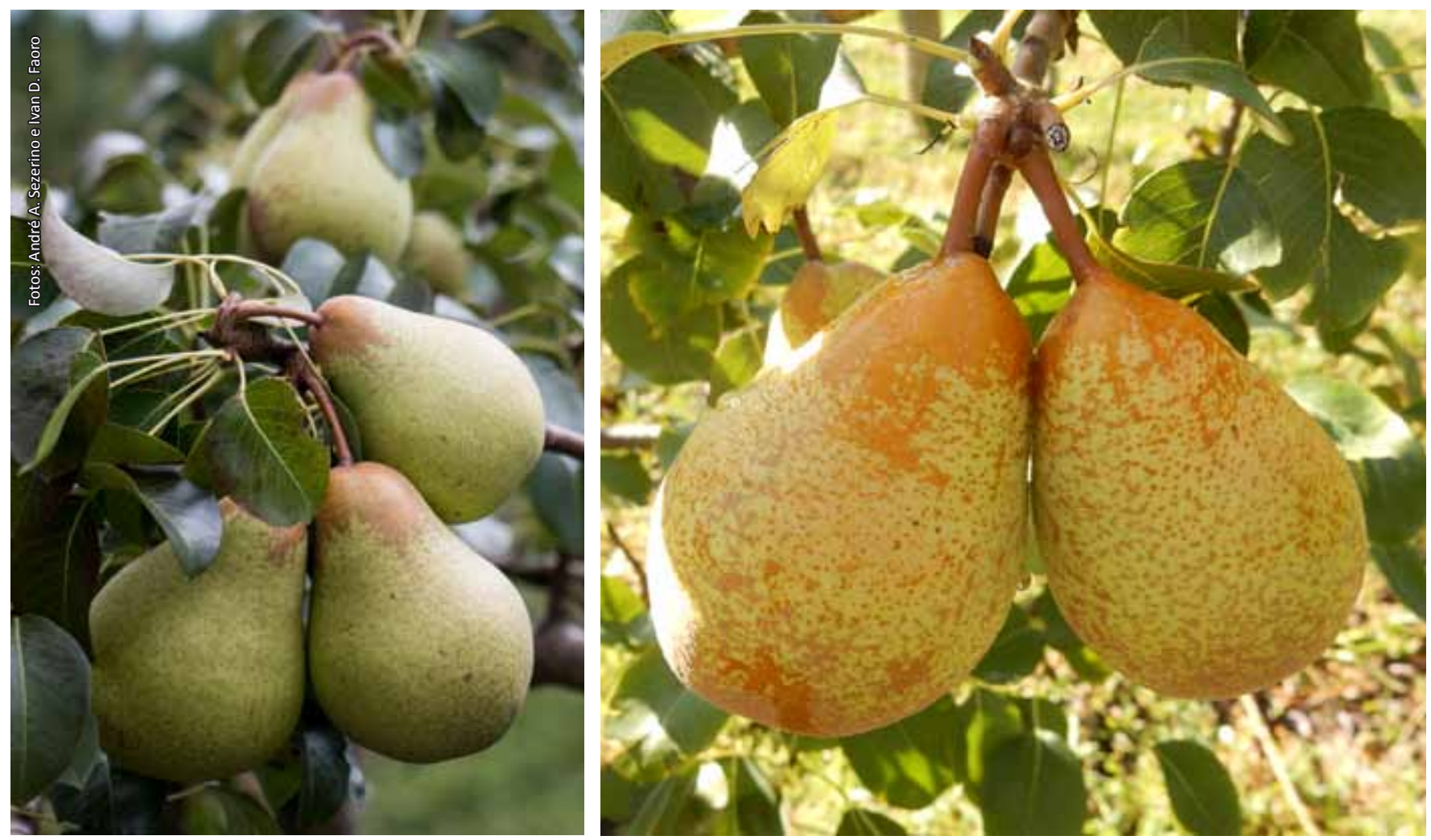

Figura 1. Frutos de pera 'Rocha'.

Figure 1. Fruits of the pear "Rocha" 
a casca é sempre presente, variando a sua extensão em função das condições climáticas. São levemente aromáticos, a polpa tem coloração esbranquiçada, é fina, de macia crocante a fundente, levemente granulosa devido aos esclereídeos, suculenta, doce e não ácida.

O tamanho do fruto depende principalmente da nutrição da planta, do raleio e do regime hídrico do pomar, mas geralmente apresenta tamanho médio e calibre de 55 a $65 \mathrm{~mm}$ e peso variando normalmente entre 85 e $130 \mathrm{~g}$.

A colheita ocorre ao final de janeiro e no início de fevereiro. Para determinar o ponto de colheita de peras 'Rocha' é recomendado verificar a firmeza de polpa, medida com penetrômetro munido de ponteira com $8 \mathrm{~mm}$ de diâmetro. Para frutos produzidos no Brasil e destinados à armazenagem, a colheita deve ser realizada quando a firmeza de polpa estiver variando entre 60 e 70N (6,1 e 7,1kgf) (MARTIN et al., 2015a).

A pera 'Rocha' não é capaz de atingir qualidade própria para o consumo na planta. Quando se tem por objetivo a comercialização imediata dos frutos, recomenda-se expô-los durante 15 dias a $3^{\circ} \mathrm{C}$, o que proporciona amadurecimento adequado após exposição à temperatura ambiente. Também a aplicação exógena de etileno pode induzir o amadurecimento dos frutos (MARTIN et al., 2015b).

Apresenta elevada resistência ao manuseio, transporte e armazenagem pós-colheita, suportando até seis meses em câmaras frigoríficas comuns, com temperatura entre $-0,5^{\circ} \mathrm{C}$ e $0^{\circ} \mathrm{C}$ e umidade relativa (UR) de $93 \%$ a $96 \%$. A capacidade de conservação está relacionada à qualidade dos frutos e, quando armazenados em refrigeração, pode ser ampliada em cerca de 30 dias quando os frutos são acondicionados em filme de polietileno de baixa densidade linear $(100 \mu \mathrm{m})$ com aditivo BIF 1.500 6\%.

Em câmara de atmosfera controlada, dependendo do local de origem dos frutos, as concentrações de $0,5 \mathrm{kPa} \mathrm{O}_{2}+$ $<0,03 \mathrm{kPaCO}$ e $1,0 \mathrm{kPaO} \mathrm{CP}_{2}+1,0 \mathrm{kPa}$ $\mathrm{CO}_{2}$ são as mais indicadas para propiciar o amadurecimento adequado após a armazenagem. Nessas condições, podem tolerar até nove meses de armazenagem. Todavia, os frutos são pouco tolerantes a pressões parciais muito elevadas de $\mathrm{CO}_{2}$, como $3,0 \mathrm{kPa}$. Peras com baixa relação $\mathrm{K} / \mathrm{Ca}$ e teores mais elevados de Ca na polpa são menos suscetíveis ao escurecimento desta. O tratamento com 1-metilciclopropeno (1-MCP) pode ser uma alternativa para prolongar o período de armazenagem de peras 'Rocha'. Porém, doses elevadas (acima de $150 \mathrm{~nL} \mathrm{~L}^{-1}$ ) podem comprometer o amadurecimento dos frutos durante a comercialização, especialmente em frutos colhidos mais verdes.

Ao saírem da câmara fria, os frutos atingem a maturação cerca de cinco a oito dias depois, quando expostos a temperaturas de 18 a $20^{\circ} \mathrm{C}$. Para consumo, deve apresentar cerca de $13 \%$ de sólidos solúveis e firmeza da polpa de 20 a 30N (HENDGES \& ESPÍNDOLA, 2012).

\section{Considerações finais}

Nos últimos 15 anos, o cv. Rocha vem despontando como a pereira mais plantada em Santa Catarina. Seus atributos são a média exigência em frio hibernal, a boa produtividade, a alta qualidade dos frutos para consumo in natura, e a boa resistência ao transporte e à armazenagem.

\section{Referências}

FAORO, I.D.; PASA, M.S. da; SEZERINO, A.A.; KATSURAYAMA, J.M.; PETRI, J.L.; KVITSCHAL, M.V. Pera. In: EMPRESA DE PESQUISA AGROPECUÁRIA E EXTENSÃO RURAL DE SANTA CATARINA. Avaliação de cultivares para o estado de Santa Catarina 2017-2018. Florianópolis: Epagri, 2017. p.61-65. (Epagri. Boletim Técnico, 176).

FIORAVANÇO, J.C.; ANTONIOLLI, L.R.; CZERMAINSKI, A.B.C.; OLIVEIRA, P.R.D. de; ALMEIDA, G.K. de; ARAÚJO, W.F. de. Avaliação agronômica da pereira 'Rocha' em Vacaria, RS. Bento Gonçalves: Embrapa Uva e Vinho, 2016. 12p. (Circular Técnica, 128).

HENDGES, M.V.; ESPÍNDOLA, B.P. Colheita e pós-colheita. In: A cultura da pereira. Florianópolis: DIOESC, 2012. p.228-247.

MARTIN, M.S.; STEFFENS, C.A.; AMARANTE, C.V.T.; BRACKMANN, A.; LINKE JUNIOR., W. Qualidade de peras 'Rocha' armazenadas em atmosfera controlada. Revista Brasileira de Fruticultura, Jaboticabal, v.37, n.1, p.7382, 2015a.

MARTIN, M.S.; STEFFENS, C.A.; AMARANTE, C.V.T.; HENDGES, M.V.; ANTONIOLLO, L.R.; DENARDI, V. Indução do amadurecimento de peras 'Rocha' submetidas à baixa temperatura e à aplicação de etileno. Pesquisa Agropecuária Brasileira, Brasília, DF, v.50, n.4, p.273-281, 2015b.

SEZERINO, A.A.; ORTH, A.I. Polinização da pereira-portuguesa em Bom Retiro-SC, Brasil. Revista Brasileira de Fruticultura, Jaboticabal, v.37, n.4, p.943-951, 2015.

SOARES, J. (Coord.); SILVA, A.; ALEXANDRE, J. O livro da pera Rocha, Cadaval: ANP, 2001. v.1. $184 p$.

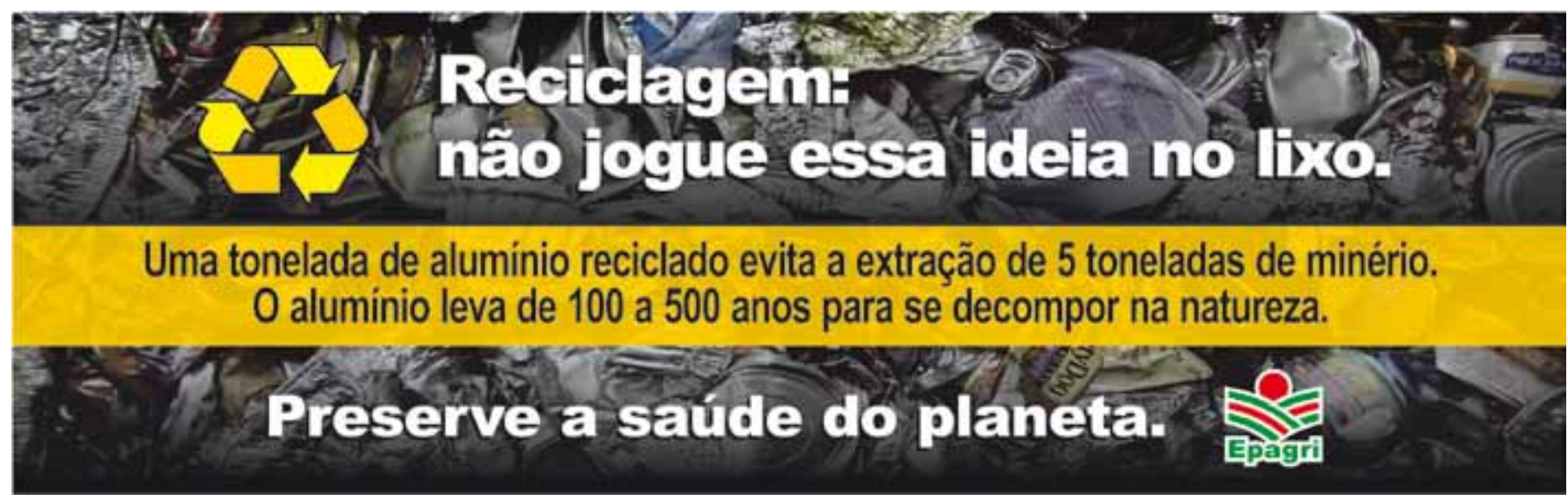

